\title{
Resíduos da indústria de canudos plásticos descartáveis: influência do tratamento alcalino sobre as propriedades de peças de concreto para pavimento intertravado
}

\author{
Elis Machado de Oliveira ${ }^{1^{*}}$ (1) \\ Elen Machado de Oliveira ${ }^{1}$ \\ Camila Machado de Oliveira ${ }^{2}$ \\ Alexandre Gonçalves Dal-Bó ${ }^{1}$ \\ Michael Peterson ${ }^{1}$
}

\section{Resumo}

Considerando a quantidade de aparas geradas na produção de canudos descartáveis, o potencial deste resíduo como material de reforço em peças de concreto para pavimento intertravado foi avaliado. As aparas, após o processo de cominuição, foram submetidas a um tratamento superficial com solução de hidróxido de sódio nas concentrações de 0,25 e $0,50 \mathrm{M}(\mathrm{mol} / \mathrm{L})$ e introduzidas no concreto em teores volumétricos de 0,$25 ; 0,50$ e $0,75 \%$. As propriedades de resistência à compressão (28 dias), tração na flexão e absorção de água das diferentes composições foram investigadas. A resistência à compressão aos 28 dias das amostras com a adição das aparas de canudos foi inferior à da referência, mas respeitou 0 limite de 35 MPa determinado pela ABNT NBR 9781 (2013). O tratamento superficial alcalino das aparas permitiu uma melhor aderência entre o material de reforço e a matriz, reduzindo a absorção de água dos pavers.

Palavras-chave: Concreto; Material de reforço; Aparas de canudos.

\section{Waste from the industry of disposable plastic straws: influence of the alkaline treatment on the properties of concrete parts for interlocking pavements}

\begin{abstract}
Considering the amount of shavings generated in the production of disposable straws, the potential of this waste as reinforcement material in interlocking pavement concrete was evaluated. The shavings, after the comminution process, were surface treated with sodium hydroxide solution at concentrations of 0.25 and $0.5 \mathrm{M}(\mathrm{mol} / \mathrm{L})$ and introduced in the concrete in volumetric contents of $0.25,0.5$ and $0.75 \%$. The properties of compressive strength (28 days), flexural tensile strength and water absorption of the different compositions were investigated. The compressive strength at 28 days of the samples with the addition of straw shavings was lower than the reference, but respected the $35 \mathrm{MPa}$ limit determined by ABNT NBR 9781 (2013). The alkaline surface treatment of the shavings allowed better adhesion between the reinforcement material and the matrix, reducing the water absorption of the pavers.
\end{abstract}

Keywords: Concrete; Reinforcement material; Straw shavings.

\section{Introdução}

Como os plásticos são empregados em diversos produtos, a produção mundial cresceu significativamente nas últimas décadas, passando de 0,5 milhão de toneladas em 1950 [1] para 348 milhões de toneladas em 2017 [2]. Em virtude disso, a geração de resíduos tornou-se um problema ambiental global, pois a maior parte do material descartado é aterrada ou incinerada, e apenas um pequeno percentual é reciclado [3].

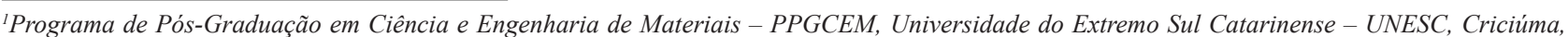
SC, Brasil.

${ }_{2}^{2}$ Programa de Pós-Graduação em Ciência e Engenharia de Materiais - PGMAT, Universidade Federal de Santa Catarina - UFSC, Florianópolis, SC, Brasil.

*Autor correspondente: elismdeoliveira@hotmail.com 
O setor da construção civil, por sua representatividade no cenário mundial, é fortemente influenciado a buscar materiais mais sustentáveis [4]. Uma maneira de viabilizar a sustentabilidade na construção civil é a reutilização de resíduos, sendo que na produção do concreto, muitos deles podem ser inseridos. Dessa forma, introduzi-los ao processo configura uma maneira útil e eficiente de aplicação, pois o concreto é um dos materiais mais utilizados nesse ramo [5].

As fibras de polipropileno, por serem de natureza hidrofóbica, frequentemente apresentam uma má ligação com os compósitos de concreto [6]. Estudos apontam que o tratamento alcalino dessas fibras melhora a adesão à matriz cimentícia, pois modificações superficiais incluem um aumento da rugosidade. A maior adesão proporciona melhores propriedades mecânicas ao concreto quando comparado ao compósito com fibras sem tratamento [7].

O pavimento intertravado, pela facilidade de construção, permite a rápida substituição das peças de concreto danificadas, promovendo menos desperdícios de material e horas trabalhadas, tornando-o mais sustentável em relação às estruturas convencionais de asfalto e concreto [8].

O uso de fibras em peças de concreto para pavimentos eleva a resistência à compressão, flexão, ao impacto e abrasão, aumentando a qualidade e vida útil (durabilidade) dos blocos [9].

Embora historicamente os canudos fossem feitos de papel, na atualidade o polipropileno é o material mais comum, pois apresenta diversas propriedades que o tornam adequado para este fim [10].

Diferentes tipos de resíduos de polipropileno oriundos da produção de tubos foram empregados em compósitos leves a base de cimento em substituição aos agregados finos e promoveram uma redução gradual das propriedades mecânicas com o aumento do teor de substituição [11]. Porém, não há trabalhos que avaliaram canudos descartáveis como material de reforço em concreto e o efeito do tratamento superficial alcalino destes resíduos sobre as propriedades do produto final.

No Brasil, o Distrito Federal, Espírito Santo, Maranhão, Rio Grande do Norte e Santa Catarina sancionaram leis que proíbem o uso de canudos plásticos [12]. Mas, mundialmente, esses artefatos representam cerca de $4 \%$ de todo o lixo plástico [13] e por isso, neste trabalho, estudou-se a viabilidade das aparas de canudos descartáveis como reforço em peças de concreto para pavimento intertravado, buscando contribuir para a valorização do resíduo e redução deste material em aterros sanitários.

\section{Materiais e métodos}

As aparas de canudos foram fornecidas por uma empresa do município de São Ludgero (Santa Catarina), sendo compostas por polipropileno e apresentando massa específica, avaliada por picnometria a gás hélio em picnômetro

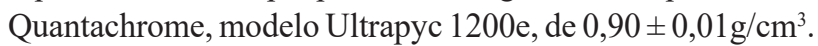
As caracterizações dos agregados miúdo e graúdo encontram-se na Tabela 1.

Para o tratamento superficial do resíduo, utilizou-se o hidróxido de sódio P.A. (Dinâmica Química Contemporânea Ltda, pureza $\geq 97 \%$ ). O cimento escolhido foi o CP V ARI ABNT NBR 16697 [14], com massa específica de 3,14 g/ $\mathrm{cm}^{3}$.

As aparas de canudos, após o corte em segmentos de $4 \mathrm{~cm}$, foram conduzidas a um liquidificador caseiro (marca Britânia) para adequar a forma e o tamanho do resíduo (Figura 1) à incorporação no concreto. Posteriormente ao processo de cominuição, para melhorar a aderência com a matriz de concreto, passaram por um tratamento alcalino em solução de hidróxido de sódio nas concentrações de $0,25 \mathrm{M}$ e 0,50 M. Amostras de $150 \mathrm{~g}$ foram imersas em 2 litros de solução e o sistema permaneceu sob agitação mecânica durante duas horas. Ao final do processo, o material foi lavado com água deionizada e seco.

As resistências à tração (descritas na Tabela 2) foram determinadas com base nas prescrições da ASTM C1557 [20]. Para cada tratamento superficial, utilizaram-se cinco canudos com comprimentos de dez centímetros que foram tracionados em máquina universal de ensaios mecânicos EMIC DL 10000 com velocidade de carregamento de $300 \mathrm{~mm} / \mathrm{min}$.

A dosagem do concreto empregada em massa foi de 1:1,5:1,5:2,5, equivalente ao consumo de materiais por metro cúbico de concreto de $347 \mathrm{~kg}: 520,5 \mathrm{~kg}$ : $520,5 \mathrm{~kg}$ :

Tabela 1. Caracterização dos agregados miúdo e graúdo

\begin{tabular}{|c|c|c|c|}
\hline Característica / Norma(s) & Areia fina & Areia grossa & Brita \\
\hline Massa específica $\left(\mathrm{g} / \mathrm{cm}^{3}\right)$ & \multirow[t]{2}{*}{2,58} & \multirow[t]{2}{*}{2,49} & \multirow[t]{2}{*}{3,02} \\
\hline ABNT NBR NM 52 [15] e ABNT NBR & & & \\
\hline Massa unitária $\left(\mathrm{kg} / \mathrm{m}^{3}\right)$ & \multirow[t]{2}{*}{$1.415,0$} & \multirow[t]{2}{*}{$1.593,0$} & \multirow[t]{2}{*}{$1.496,0$} \\
\hline ABNT NBR NM 45 [17] & & & \\
\hline Absorção de água (\%) & \multirow[t]{2}{*}{0,94} & \multirow[t]{2}{*}{0,81} & \multirow[t]{2}{*}{0,93} \\
\hline ABNT NBR NM 30 [18] e ABNT NBR & & & \\
\hline Dimensão máxima característica (mm) & \multirow[t]{2}{*}{0,60} & \multirow[t]{2}{*}{4,75} & \multirow[t]{2}{*}{9,50} \\
\hline ABNT NBR 248 [19] & & & \\
\hline Módulo de finura & \multirow[t]{2}{*}{1,05} & \multirow[t]{2}{*}{2,92} & \multirow[t]{2}{*}{5,67} \\
\hline ABNT NBR 248 [19] & & & \\
\hline
\end{tabular}




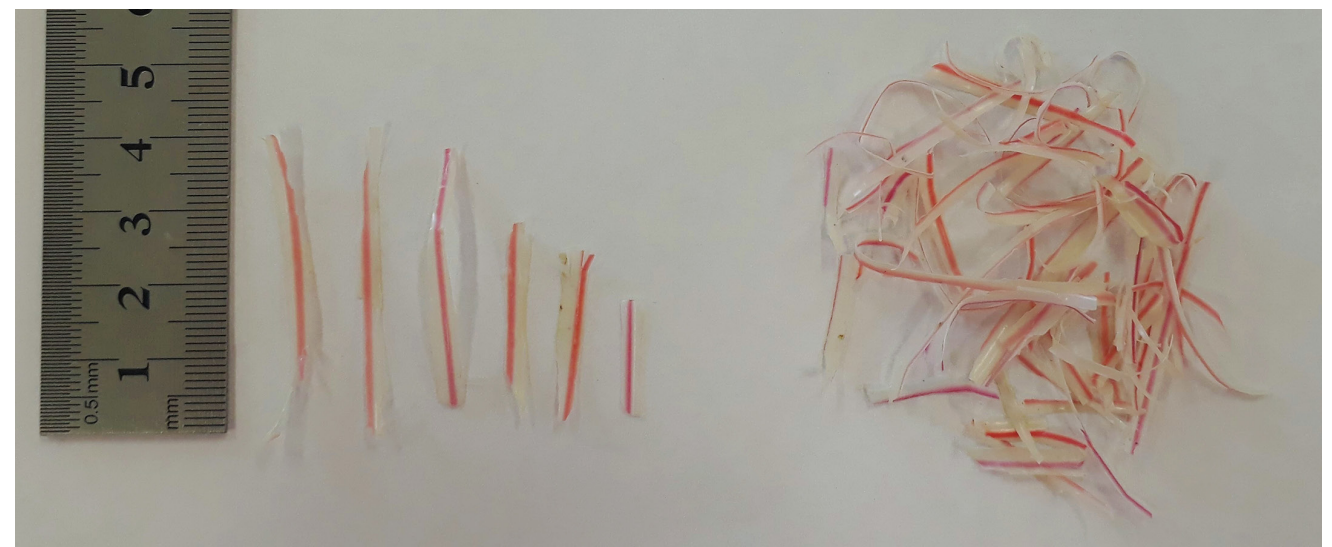

Figura 1. Aparas de canudos após segmentação.

Tabela 2. Resistência à tração das aparas de canudos descartáveis

\begin{tabular}{ccc}
\hline Tratamento superficial & Resistência à tração (MPa) & Desvio padrão (MPa) \\
\hline Sem tratamento & 29,25 & 3,72 \\
$0,25 \mathrm{M}$ & 27,79 & 1,02 \\
$0,50 \mathrm{M}$ & 28,85 & 3,93 \\
\hline
\end{tabular}

Tabela 3. Matriz de dados do planejamento fatorial $2^{2}+3$

\begin{tabular}{ccccc}
\hline \multirow{2}{*}{ Experimento } & Níveis & & Fatores \\
\cline { 3 - 5 } & & & Teor de resíduo (\%) & $\begin{array}{c}\text { Concentração da solução } \\
\text { de NaOH (M) }\end{array}$ \\
\hline 1 & -1 & -1 & 0,25 & 0,00 \\
2 & +1 & +1 & 0,75 & 0,00 \\
3 & -1 & +1 & 0,25 & 0,50 \\
4 & +1 & 0 & 0,75 & 0,50 \\
5 & 0 & 0 & 0,50 & 0,25 \\
6 & 0 & 0 & 0,50 & 0,25 \\
7 & 0 & 0,50 & 0,25 \\
\hline
\end{tabular}

$867,5 \mathrm{~kg}$ para cimento, areia fina, areia grossa e brita $\mathrm{n}^{\circ} 0$, respectivamente. Aplicou-se a relação água/cimento de 0,55 para todas as diferentes composições, que se distinguem pelo teor volumétrico de aparas de canudos incorporado (0,25\%, $0,50 \%$ e $0,75 \%$ ) em função do volume de concreto. A massa de resíduo que corresponde a cada volume foi obtida por meio da massa específica do material.

Parâmetros como teor de fibras e a concentração de hidróxido de sódio utilizada no tratamento químico das aparas de canudos foram definidos segundo a metodologia estatística de um planejamento fatorial $2^{\mathrm{k}}$ com dois fatores e um ponto central em triplicata, apresentado na Tabela 3.

As variáveis respostas do planejamento descrito foram a resistência à tração na flexão, absorção de água e resistência à compressão aos 28 dias. Avaliaram-se os dados com o software Statistica 13.0 Trial Version com os resultados de todas as amostras, não somente com a média.

A mistura dos materiais foi realizada conforme as especificações da ABNT NBR 12821 [21]. A moldagem e cura dos corpos de prova seguiu o que prescreve a ABNT NBR 5738 [22].
O concreto foi inserido em uma única camada e o adensamento foi realizado em mesa vibratória por tempo suficiente para a distribuição uniforme da mistura no molde. Após a moldagem, mantiveram-se os corpos de prova em local protegido de intempéries e cobertos para evitar a perda de água. A desmoldagem ocorreu após 24 horas para todos os corpos de prova, sendo eles encaminhados na sequência para o tanque de cura com temperatura de $23 \pm 2{ }^{\circ} \mathrm{C}$ por 28 dias.

A massa específica foi investigada segundo a metodologia da ABNT NBR 9778 [23] com 5 corpos de prova cilíndricos de $10 \mathrm{~cm}$ x $20 \mathrm{~cm}$ para cada composição.

$\mathrm{O}$ procedimento do ensaio de resistência à tração na flexão seguiu a ABNT NBR 12142 [24], sendo utilizados 3 corpos de prova prismáticos para cada composição com dimensões de $10 \mathrm{~cm}$ x $10 \mathrm{~cm}$ x $35 \mathrm{~cm}$ (vão de $30 \mathrm{~cm}$ ) e como dispositivo de carregamento a máquina universal de ensaios mecânicos EMIC DL 10000.

Para os ensaios de resistência à compressão aos 28 dias, 6 corpos de prova com dimensões de $10 \mathrm{~cm}$ x $20 \mathrm{~cm}$ x $6 \mathrm{~cm}$, para cada composição, passaram por capeamento e permaneceram saturados em água a $23 \pm 5^{\circ} \mathrm{C}$ até o momento 
da ruptura. O equipamento adotado foi a prensa EMIC PC 200I com velocidade de carregamento de $550 \mathrm{kPa} / \mathrm{s}$, conforme estabelece a ABNT NBR 9781 [25]. A absorção de água das peças de concreto foi avaliada segundo a metodologia descrita pela mesma norma com 4 corpos de prova para cada composição.

\section{Resultados e discussão}

A massa específica do concreto não sofreu variação entre as diferentes composições, sendo de $2,3 \mathrm{~g} / \mathrm{cm}^{3}$, resultado próximo aos encontrados na literatura [26,27]. Como o resíduo foi introduzido ao concreto como uma adição em teores volumétricos baixos $(0,25 \%, 0,50 \%$ e $0,75 \%$ ), não substituindo nenhum componente de massa específica elevada, a sua incorporação não modificou a massa específica do concreto.

A Figura 2a apresenta os resultados de absorção de água para as diferentes composições. Evidencia-se que para as peças com a incorporação do resíduo, o tratamento das aparas de canudos com solução de hidróxido de sódio reduziu a absorção de água. Para a adição de 0,25\%, comparando os experimentos 1 (aparas sem tratamento) e 3 (tratadas na concentração de $0,50 \mathrm{M}$ ), observa-se uma redução de $22,8 \%$. Já para a introdução de $0,75 \%$, experimentos 2 (aparas sem tratamento) e 4 (tratadas na concentração de 0,50 M), a redução foi de $30,9 \%$. Todos os experimentos atenderam à exigência da ABNT NBR 9781 [25], com valores de absorção de água inferiores a $6 \%$.

A Tabela 4 exibe a análise de variância ANOVA e aponta que, com 95\% de confiança, a concentração da solução de hidróxido de sódio utilizada no tratamento e a curvatura são fatores significativos ( $\mathrm{p}<\alpha$, para $\alpha=0,05)$ para a variável resposta absorção de água. Apesar dos outros fatores apresentarem um valor $\mathrm{p}>\alpha$, quando não considerados na análise estatística, reduziram o $\mathrm{R}^{2}$, prejudicando o ajuste do modelo.

A superfície de resposta da Figura 2 b indica que as maiores absorções de água ocorreram para as peças de concreto em que as aparas de canudos não foram submetidas ao tratamento superficial, sugerindo que o método melhorou a aderência do resíduo à matriz. Foi adotado o nível 0 de curvatura para a superfície de resposta, pois não foram observadas diferenças expressivas com a aplicação de valores distintos de curvatura.

O tratamento superficial permitiu uma melhor compatibilidade entre o resíduo e a matriz, reduzindo os vazios. Sabe-se que a durabilidade do concreto está intimamente relacionada com a absorção de água, pois o transporte de líquidos para o seu interior permite a entrada de íons corrosivos, como cloretos e sulfatos, que (a)

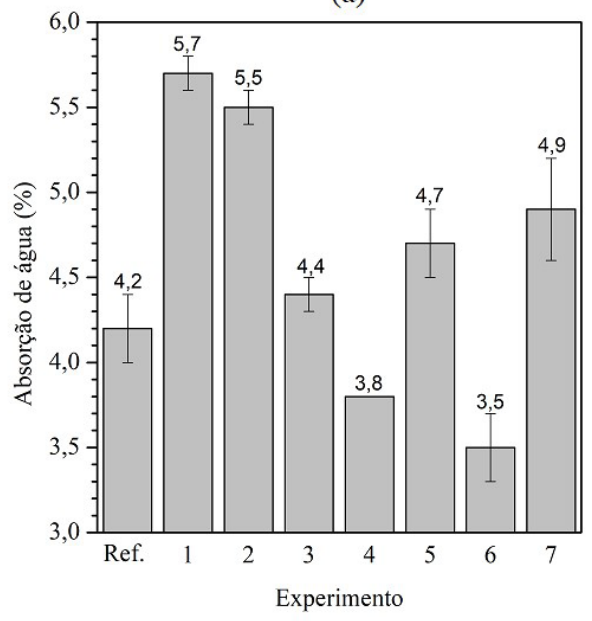

(b)

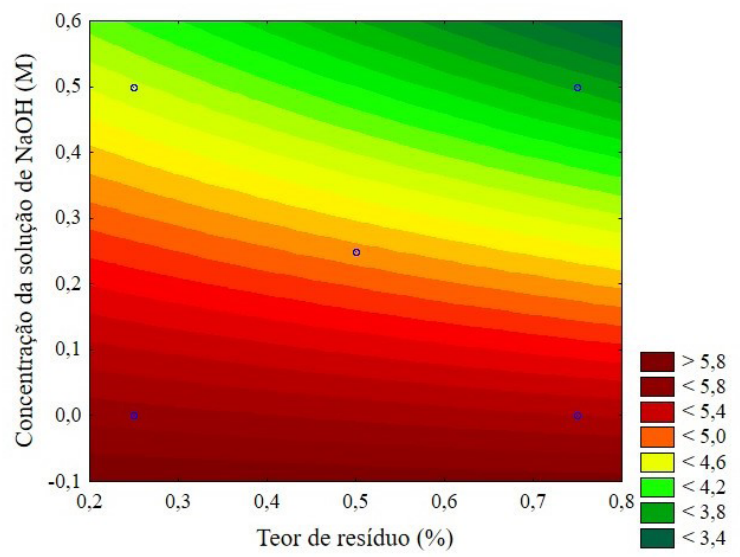

Figura 2. (a) Absorção de água das diferentes composições e (b) superfície de resposta para os resultados de absorção de água.

Tabela 4. Análise de variância ANOVA para a absorção de água

\begin{tabular}{lccccc}
\hline \multicolumn{1}{c}{ Fator } & SS & df & MS & F & p \\
\hline Curvatura & $\mathbf{1 , 8 0 1 0 7}$ & $\mathbf{1}$ & $\mathbf{1 , 8 0 1 0 7 1}$ & $\mathbf{7 , 9 8 5 4 7}$ & $\mathbf{0 , 0 0 9 5 8 3}$ \\
(1) Teor de resíduo & 0,64000 & 1 & 0,640000 & 2,83759 & 0,105606 \\
(2) Concentração da solução de NaOH & $\mathbf{8 , 7 0 2 5 0}$ & $\mathbf{1}$ & $\mathbf{8 , 7 0 2 5 0 0}$ & $\mathbf{3 8 , 5 8 4 5 8}$ & $\mathbf{0 , 0 0 0 0 0 2}$ \\
$1 \times 2$ & 0,25000 & 1 & 0,250000 & 1,10843 & 0,303358 \\
Erro & 5,18750 & 23 & 0,225543 & & \\
Total SS & 16,58107 & 27 & & \\
$\mathrm{R}^{2}$ & 0,68714 & & & \\
$\mathrm{R}^{2}$ ajustado & 0,63273 & & & \\
$\alpha$ & 0,05 & & & \\
\hline
\end{tabular}


colaboram diretamente com o processo de deterioração físico-química [28].

Para todos os corpos de prova, a ruptura no ensaio de resistência à tração na flexão ocorreu no terço médio e os valores de resistência são apresentados na Figura 3a. Para as amostras com a incorporação de resíduo sem tratamento e tratado na concentração de $0,50 \mathrm{M}$, a adição das aparas de canudos em um teor mais elevado acarretou na redução da resistência à tração na flexão.

Exceto para o experimento 1, os resultados demonstraram que o resíduo não foi eficiente para elevar a resistência à tração na flexão do concreto, mas ele permitiu que mesmo após a ruptura, o corpo de prova não se fragmentasse, como mostra a Figura $3 b$.

A análise de variância ANOVA da Tabela 5 aponta que os fatores teor de resíduo e a concentração da solução de hidróxido de sódio utilizada no tratamento são significativos para a variável resposta resistência à tração na flexão. A interação entre os fatores, apesar de não significativa, se excluída, reduz o $\mathrm{R}^{2}$, prejudicando o ajuste do modelo.

A maior resistência à tração na flexão estar vinculada a menores teores de resíduo incorporados (Figura 4a) denota que, apesar do tratamento modificar a superfície do material, a ancoragem não foi suficiente para que funcionasse como ponte de transferência de tensões na matriz de concreto, o que pode estar relacionado com a baixa resistência à tração das aparas de canudos.

Para um mesmo teor de resíduo, a resistência à tração na flexão reduz à medida que a concentração de $\mathrm{NaOH}$ aumenta, indicando que possíveis traços de sódio podem ter afetado a resistência da matriz de concreto. A reação entre álcalis e alguns constituintes mineralógicos dos agregados provoca a expansibilidade e perda de resistência mecânica do concreto, acarretando na sua deterioração [29].

Alguns autores descreveram um decaimento médio de $9 \%$ na resistência à tração na flexão do concreto com a dosagem de até $1 \%$ em volume de fibra de resíduo de plástico metalizado, demonstrando que a resistência do concreto simples era resultado da resistência da matriz. Contudo, a característica de deformação por flexão foi melhorada pela incorporação da fibra, fato semelhante ao que aconteceu neste trabalho [30].

Considerando que a resistência é governada pela matriz cimentícia, para um mesmo volume de concreto, o volume de matriz é reduzido na proporção em que o teor de resíduo é incorporado, provocando uma queda na resistência, pois a apara não possui as mesmas propriedades dos constituintes do concreto.

A Tabela 6 traz a resistência à compressão aos 28 dias das diferentes composições. Com exceção do experimento 4, (a)

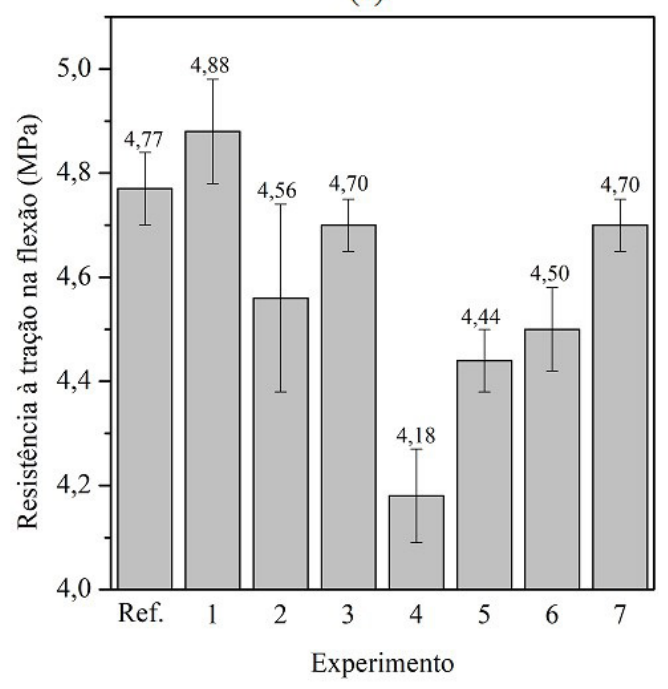

(b)

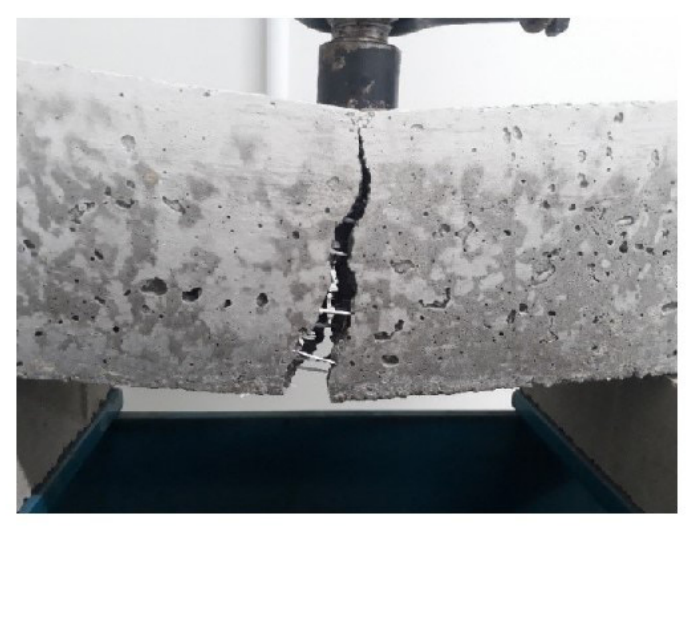

Figura 3. (a) Resistência à tração na flexão das diferentes composições e (b) corpo de prova com a incorporação do resíduo após a ruptura.

Tabela 5. Análise de variância ANOVA para a resistência à tração na flexão

\begin{tabular}{lcccc}
\hline \multicolumn{1}{c}{ Fator } & SS & df & MS & F \\
\hline (1) Teor de resíduo & $\mathbf{0 , 5 2 5 0 0 8}$ & $\mathbf{1}$ & $\mathbf{0 , 5 2 5 0 0 8}$ & $\mathbf{3 5 , 9 5 3 4 4}$ \\
(2) Concentração da solução de NaOH & $\mathbf{0 , 2 3 2 4 0 8}$ & $\mathbf{1}$ & $\mathbf{0 , 2 3 2 4 0 8}$ & $\mathbf{1 5 , 9 1 5 7 1}$ \\
$1 \times 2$ & 0,031008 & 1 & 0,031008 & 0,014602 \\
Erro & 0,248242 & 17 & \\
Total SS & 1,036667 & 20 & \\
$\mathrm{R}^{2}$ & 0,76054 & & \\
$\mathrm{R}^{2}$ ajustado & 0,71828 & & \\
$\alpha$ & 0,05 & & \\
\hline
\end{tabular}


todos os outros atenderam à resistência mínima de $35 \mathrm{MPa}$ exigida pela ABNT NBR 9781 [25].

A introdução do resíduo na matriz cimentícia reduziu a resistência a compressão das amostras. Em outras pesquisas também foi verificada uma redução da propriedade após a adição de fibras de resíduo de plástico metalizado em teores volumétricos entre 0 e $2 \%$ [30].

A Tabela 7 expõe a análise de variância ANOVA para a resistência à compressão aos 28 dias, demonstrando que os fatores teor de resíduo e a concentração da solução de hidróxido de sódio utilizada no tratamento, bem como a interação entre eles, são significativos para a variável resposta.

Tabela 6. Resistência à compressão aos 28 dias das diferentes composições

\begin{tabular}{cc}
\hline Experimento & $\begin{array}{c}\text { Resistência à compressão } \\
\text { (MPa) }\end{array}$ \\
\hline Referência & $43,61 \pm 2,16$ \\
1 & $44,18 \pm 2,84$ \\
2 & $35,26 \pm 1,26$ \\
3 & $37,70 \pm 0,49$ \\
4 & $34,52 \pm 1,33$ \\
5 & $37,22 \pm 1,88$ \\
6 & $38,31 \pm 0,98$ \\
7 & $36,47 \pm 1,63$ \\
\hline
\end{tabular}

A superfície de resposta da Figura 4 b revela que conciliando menores teores de resíduo e baixas concentrações da solução de hidróxido de sódio, melhores resultados de resistência à compressão são alcançados para as peças de concreto, assim como constatado para a resistência à tração na flexão, evidenciando que a modificação superficial do resíduo pelo tratamento alcalino não foi eficiente como alternativa para melhorar a resistência mecânica do concreto com adição de aparas de canudos. Neste caso, não houve uma relação direta entre a porosidade do concreto e a resistência à compressão, já que as maiores absorções de água ocorreram para as peças de pavimento intertravado com a adição do resíduo sem tratamento.

$\mathrm{Na}$ Figura 4b, para os menores teores de resíduo, nota-se que a resistência à compressão decai à medida que a concentração de solução de hidróxido de sódio aumenta, dando indícios de que o sódio, possivelmente presente na superfície do material, pode ter afetado a resistência mecânica do concreto [29]. Já para maiores teores de resíduo, a concentração da solução de $\mathrm{NaOH}$ mais elevada não promoveu grandes alterações na resistência à compressão aos 28 dias. É provável que haja um equilíbrio entre o desempenho das aparas na retenção da abertura das fissuras e a menor resistência da matriz de concreto.

Tabela 7. Análise de variância ANOVA para a resistência à compressão aos 28 dias

\begin{tabular}{lccccc}
\hline \multicolumn{1}{c}{ Fator } & SS & df & MS & F & p \\
\hline (1) Teor de resíduo & $\mathbf{2 1 9 , 6 1 5 0}$ & $\mathbf{1}$ & $\mathbf{2 1 9 , 6 1 5 0}$ & $\mathbf{7 7 , 3 6 0 3 5}$ & $\mathbf{0 , 0 0 0 0 0 0}$ \\
(2) Concentração da solução de NaOH & $\mathbf{7 8 , 3 3 7 1}$ & $\mathbf{1}$ & $\mathbf{7 8 , 3 3 7 1}$ & $\mathbf{2 7 , 5 9 4 5 8}$ & $\mathbf{0 , 0 0 0 0 0 6}$ \\
$\mathbf{1} \times \mathbf{2}$ & $\mathbf{4 9 , 4 2 1 4}$ & $\mathbf{1}$ & $\mathbf{4 9 , 4 2 1 4}$ & $\mathbf{1 7 , 4 0 8 9 1}$ & $\mathbf{0 , 0 0 0 1 6 9}$ \\
Erro & 107,8766 & 38 & 2,8389 & \\
Total SS & 455,2500 & 41 & & \\
$\mathrm{R}^{2}$ & 0,76304 & & & \\
$\mathrm{R}^{2}$ ajustado & 0,74433 & & & \\
$\alpha$ & 0,05 & & & \\
\hline
\end{tabular}

(a)

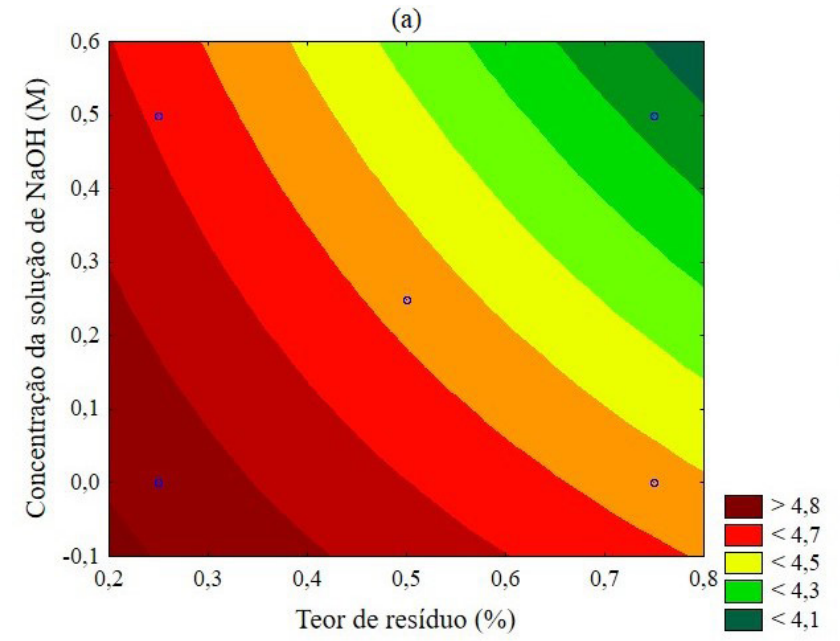

(b)

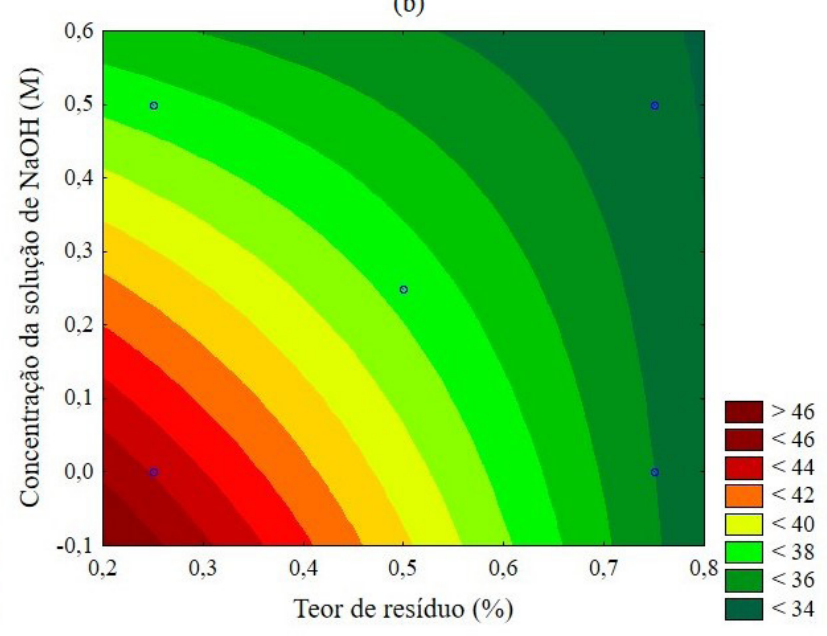

Figura 4. (a) Superfície de resposta para os resultados de resistência à tração na flexão e (b) superfície de resposta para os resultados de resistência à compressão aos 28 dias. 


\section{Conclusões}

As peças de concreto com a adição das aparas de canudos descartáveis apresentaram, no geral, uma redução das propriedades mecânicas e uma maior absorção de água quando comparadas com as amostras de referência. Ao ser adicionado ao concreto, o resíduo ocasiona uma redução do volume de matriz cimentícia, principal responsável pela resistência mecânica. Por isso, para as propriedades de resistência à tração na flexão e compressão aos 28 dias, o menor teor volumétrico de resíduo sem tratamento $(0,25 \%)$ concilia os melhores resultados.

A absorção de água das peças de pavimento intertravado não foi afetada pelo teor de aparas, mas sim pela concentração da solução empregada no tratamento superficial. O tratamento superficial possibilitou que a absorção de água fosse reduzida, sendo que a concentração mais elevada adotada do planejamento experimental $(0,50 \mathrm{M})$ foi a mais eficiente.

Embora o resíduo não tenha funcionado como material de reforço na matriz cimentícia, as peças de concreto com a sua incorporação mantêm a integridade após a fissuração. Dessa forma, empregá-lo no pavimento é uma maneira de reduzir a sua deposição em aterros sanitários e o descarte inadequado.

\section{Agradecimentos}

Os autores agradecem à Coordenação de Aperfeiçoamento de Pessoal de Nível Superior (CAPES/Brasil) e à Fundação de Amparo à Pesquisa e Inovação do Estado de Santa Catarina (FAPESC/Brasil) pelas bolsas de estudos concedidas.

\section{Referências}

1 Thompson RC, Moore CJ, vom Saal FS, Swan SH. Plastics, the environment and human health: current consensus and future trends. Philosophical Transactions of the Royal Society B: Biological Sciences. 2009;364(1526):2153-2166.

2 PlasticsEurope. Plastics - the facts 2018: an analysis of European plastics production, demand and waste data. Bruxels: Association of Plastics Manufacturers; 2018 [acesso em 12 ago. 2020]. Disponível em: https://www. plasticseurope.org/application/files/6315/4510/9658/Plastics_th\%0Ae_facts_2018_AF_web.pdf.

3 Wagner TP. Sustainability and Plastic Waste. In: Ferranti P, Berry EM, Anderson JR. Encyclopedia of Food Security and Sustainability. Amsterdam: Elsevier; 2019. pp. 588-92.

4 Kutnik M, Suttie E, Brischke C. Durability, efficacy and performance of bio-based construction materials: Standardisation background and systems of evaluation and authorisation for the European market. In: Jones D, Brischke C. Performance of Bio-based Building Materials. Amsterdam: Elsevier; 2017. pp. 593-610.

5 Gill AS, Siddique R. Durability properties of self-compacting concrete incorporating metakaolin and rice husk ash. Construction \& Building Materials. 2018;176:323-332.

6 Akand L, Yang M, Wang X. Effectiveness of chemical treatment on polypropylene fibers as reinforcement in pervious concrete. Construction \& Building Materials. 2018;163:32-39.

7 López-Buendía AM, Romero-Sánchez MD, Climent V, Guillem C. Surface treated polypropylene (PP) fibres for reinforced concrete. Cement and Concrete Research. 2013;54:29-35.

8 Murugan RB, Natarajan C, Chen SE. Material development for a sustainable precast concrete block pavement. Journal of Traffic and Transportation Engineering. 2016;3(5):483-491.

9 Navya G, Rao JV. Experimental investigation on properties concrete paver block with the inclusion of natural fibers. International Journal of Engineering Research and Applications. 2014;4(8):34-38.

10 Schueller R. Drinking straw. How prod are made [internet] [acesso em 12 ago. 2020]. Disponível em: http://www. madehow.com/Volume-4/Drinking-Straw.html.

11 Záleská M, Pavlíková M, Pokorný J, Jankovský O, Pavlík Z, Černý R. Structural, mechanical and hygrothermal properties of lightweight concrete based on the application of waste plastics. Construction \& Building Materials. 2018;180:1-11.

12 Cidades inteligentes. Saiba quais as cidades que já proibiram o canudo plástico [internet] [acesso em 12 ago. 2020]. Disponível em: https://ci.eco.br/saiba-quais-as-cidades-que-ja-proibiram-o-canudo-plastico/.

13 Carpallo SC. Começa segunda guerra de canudos [internet] [acesso em 12 ago. 2020]. Disponível em: https://brasil. elpais.com/brasil/2017/04/26/internacional/1493243502_138078.html.

14 Associação Brasileira de Normas Técnicas. ABNT NBR 16697: Cimento Portland - requisitos. Rio de Janeiro: ABNT; 2018. 
15 Associação Brasileira de Normas Técnicas. ABNT NBR NM 52: Agregado miúdo - determinação da massa específica e massa específica aparente. Rio de Janeiro: ABNT; 2009.

16 Associação Brasileira de Normas Técnicas. ABNT NBR NM 53: Agregado graúdo - determinação da massa específica, massa específica aparente e absorção de água. Rio de Janeiro: ABNT; 2009.

17 Associação Brasileira de Normas Técnicas. ABNT NBR NM 45: Agregados - determinação da massa unitária e do volume de vazios. Rio de Janeiro: ABNT; 2006.

18 Associação Brasileira de Normas Técnicas. ABNT NBR NM 30: Agregado miúdo - determinação da absorção de água. Rio de Janeiro: ABNT; 2001.

19 Associação Brasileira de Normas Técnicas. ABNT NBR NM 248: Agregados - determinação da composição granulométrica. Rio de Janeiro: ABNT; 2003.

20 American Society for Testing and Materials. ASTM C1557: Standard test method for tensile strength and young's modulus of fibers. West Conshohocken: ASTM; 2020.

21 Associação Brasileira de Normas Técnicas. ABNT NBR 12821: Preparação de concreto em laboratório Procedimento. Rio de Janeiro: ABNT; 2009.

22 Associação Brasileira de Normas Técnicas. ABNT NBR 5738: Concreto - Procedimento para moldagem e cura de corpos de prova. Rio de Janeiro: ABNT; 2016.

23 Associação Brasileira de Normas Técnicas. ABNT NBR 9778: Argamassa e concreto endurecidos - determinação da absorção de água, índice de vazios e massa específica. Rio de Janeiro: ABNT; 2009.

24 Associação Brasileira de Normas Técnicas. ABNT NBR 12142: Concreto — Determinação da resistência à tração na flexão de corpos de prova prismáticos. Rio de Janeiro: ABNT; 2010.

25 Associação Brasileira de Normas Técnicas. ABNT NBR 9781: Peças de concreto para pavimentação - especificação e métodos de ensaio. Rio de Janeiro: ABNT; 2013.

26 Uygunoğlu T, Topcu IB, Gencel O, Brostow W. The effect of fly ash content and types of aggregates on the properties of pre-fabricated concrete interlocking blocks (PCIBs). Construction \& Building Materials. 2012;30:180-187.

27 Gencel O, Ozel C, Koksal F, Erdogmus E, Martínez-Barrera G, Brostow W. Properties of concrete paving blocks made with waste marble. Journal of Cleaner Production. 2012;21:62-70.

28 Nguyen MH, Nakarai K, Nishio S. Durability index for quality classification of cover concrete based on water intentional spraying tests. Cement and Concrete Composites. 2019;104:103355.

29 Islam MS, Akhtar S. A critical assessment to the performance of Alkali-Silica Reaction (ASR) in concrete. Canadian Chemical Transactions. 2013;1(4):253-266.

30 Bhogayata AC, Arora NK. Fresh and strength properties of concrete reinforced with metalized plastic waste fibers. Construction \& Building Materials. 2017;146:455-463.

Recebido em: 17 Ago. 2020

Aceito em: 4 Fev. 2021 